\title{
Heterogeneous expectations, IPO Underpricing and issuing mechanism
}

\author{
Xiao-cheng Zhang ${ }^{1 *}$, Miaomiao Zhang ${ }^{1}$, Shao-an Huang ${ }^{2}$ and Yongsheng Zhou
}

\footnotetext{
* Correspondence: zxchxj@163.com ${ }^{1}$ School of Management, Guilin University of Technology, 12 Jian gan road, Seven Star District, Guilin 541001, Peoples Republic of China Full list of author information is available at the end of the article
}

\begin{abstract}
Background: Compared with the fixed-price mechanism, the bookbuilding mechanism has not changed the Chinese IPO high underpricing. How to develop scientific and reasonable IPO pricing, and reduce the high IPO underpricing has become a major challenge for China's securities market.

Methods: In this paper, using behavioral finance theory and game theory, we build the Initial public offering (IPO) pricing and underpricing models with investors' heterogeneity based on different issuing mechanisms and provide a comparative analysis.

Results: Firstly, our models show that IPO underpricing will not be eliminated by using either fixed-price or bookbuilding mechanisms, but when the investors' heterogeneity expectation is the same, lower IPO underpricing can be obtained by the issuing of bookbuilding compared with that of fixed price. Secondly, the IPO underpricing may be larger than that under fixed price if the heterogeneity of investors under bookbuilding is larger than that under fixed price. Thirdly, the numerical analysis results provide strong support for our model.
\end{abstract}

Conclusions: These findings further explains the cause of the high IPO underpricing long-standing in China.

Keywords: Stock issuing mechanisms; Heterogeneous expectations; Underpricing; Bookbuilding; IPO

\section{Introduction}

Since China's initial public offerings (IPOs) started adopting an accumulated bidding inquiry system in 2005, the average underpricing of an IPO on its first day is still above $120 \%$ and market-oriented reform of stock issuing through bookbuilding has failed to fundamentally eliminate the IPO high underpricing phenomenon. What is the primary cause for the high underpricing of a national IPO? Why does market-oriented pricing fail to eliminate the IPO high underpricing phenomenon? Many studies have researched China's special market environment and system background, and have put forth many theoretical explanations and conjectures. However, the existing empirical research literature can only obtain relevant factors influencing IPO underpricing, but fails to theoretically explain why the IPO high underpricing phenomenon still exists under national market-oriented pricing mechanisms.

Miller (1977), Ritter (1991), and other scholars think that investor mania for secondary markets leads to IPO short-term underpricing and long-term underperformance, and indicate that high underpricing may also derive from such investor mania. A small number of scholars, such as Ljungqvist et al. (2004), have established a relation model between

\section{Springer}

(c) 2015 Zhang et al. Open Access This article is distributed under the terms of the Creative Commons Attribution 4.0 International License (http://creativecommons.org/licenses/by/4.0/), which permits unrestricted use, distribution, and reproduction in any medium, provided you give appropriate credit to the original author(s) and the source, provide a link to the Creative Commons license, and indicate if changes were made. 
investor mania and IPO short-term underpricing and long-term underperformance, and have formalized this theory. Gouldey (2006), Beneda and Zhang (2009), and Xiaocheng et al. $(2008,2011)$ further developed an IPO pricing model based on this and explained the reason for IPO high underpricing from the perspective of non-homogenous expectations of investors, but they still fail to research the theoretical influence of investor behavior on IPO underpricing under different issuing mechanisms. Chinese scholars Xiaohua et al. (2006) empirically researched national IPO pricing efficiency in different periods and concluded that national issuings through bookbuilding offers higher pricing efficiency than that of fixed price. Liao (2010) took constituent stock from the SSE 50 index as a study sample and discussed the pricing efficiency of stock from the perspective of the specific information content in individual stocks. Huang Ge and Lin (2011) started with the relation between behavior patterns of institutional investors and the pricing efficiency of the capital market, and used shareholding data of securities investment funds to empirically study the influence of funds shareholding behavior and shareholding changes on the pricing efficiency of the capital market. Domestic scholars have tried to discover the reason for the effects on national IPO efficiency from an empirical perspective, but have still failed to explain why market-oriented pricing cannot eliminate the IPO high underpricing phenomenon in China. Literature that conducts theoretical research on IPO pricing efficiency under different pricing mechanisms from the perspective of non-homogenous expectations of investors, to our knowledge, does not exist.

Used the theory of behavioral finance and game theory, we build Initial public offering (IPO) pricing and underpricing models with investors' heterogeneity based on different issuing mechanisms. We analysis how the heterogeneous expectations of investors influence IPO underpricing under different issuing mechanisms and a comparative analysis of the different issuing mechanisms is conducted.we find that IPO underpricing will not be eliminated by using either fixed-price or bookbuilding mechanisms, but when the investors' heterogeneity expectation is the same, lower IPO underpricing can be obtained by the issuing of bookbuilding compared with that of fixed price. we also find the IPO underpricing may be larger than that under fixed price if the heterogeneity of investors under bookbuilding is larger than that under fixed price. In addition, numerical analysis results provide strong support for our model and explain why high IPO underpricing under bookbuilding exists in China.

This paper is divided into five sections. In section 2, we construct IPO pricing and underpricing models. Section 3, we provide a theory analysis. Section 4, we do numerical analysis. Section 5 is the results and discussion. Section 6 concludes the paper.

Although the above mentioned literatures have included certain theoretical explanations regarding IPO high underpricing, some deficiencies still exist. These include the following. 1) In terms of research method, the assumptions in existing theoretical research do not coincide with the current national situation due to differences in Chinese and foreign issuing systems. Therefore, these theories from foreign scholars fail to fully explain why China's IPO high underpricing continues to exist. 2) Foreign scholars explain IPO high underpricing from the perspective of non-homogenous expectations of investors, but fail to theoretically explain IPO pricing efficiency under different issuing mechanisms from the perspective of non-homogenous expectations of investors. 3) Domestic scholars are mainly engaged in empirical study, and therefore, there is a lack of normative research. This paper tries to overcome the deficiencies in previous 
literature by establishing the IPO pricing and underpricing models under different issuing mechanisms from the perspective of non-homogenous expectations of investors; researching the influence of non-homogenous expectations of investors on IPO underpricing; conducting a comparative analysis of underpricing; and attempting to theoretically explain the IPO pricing efficiency problem under different issuing mechanisms according to actual issuing situations of national IPOs. We try to improve on previous studies in the following ways. First, we establish the IPO pricing and underpricing models under issuing mechanisms from the perspective of non-homogenous expectations of investors, conduct a comparative analysis of IPO pricing efficiency under different issuing mechanisms, and theoretically explain the reason why IPO high underpricing may exist in a market-oriented pricing mechanism. Second, we adopt a data analysis method to support the conclusions of this paper and verify the reason why IPO high underpricing always exists under the bookbuilding mechanism.

\section{Background}

In recent decades, the Initial Public Offerings has been the concern of financial researchers in China or abroad, in particular, the mystery of "IPO underpricing" enjoyed more in-depth study by many scholars. Short-term performance of IPO issue price generally is lower than the closing price listed on the first day, which has been referred to as IPO underpricing. Over the past three decades, many scholars carry out a study of the phenomenon, and put forward a variety of theories and hypothesis, but so far there is no theory recognized generally. Although China's stock market after more than 20 years of development, but in the IPO market high underpricing phenomenon still exists, and compared with mature capital markets, IPO underpricing is higher and high underpricing will sustain for a very long time. China's IPO underpricing anomaly has attracted a lot of the attention of scholars. Taking into account the unique combination of China's market environment and institutional background, scholars have put forward a wide range of theoretical description and speculation, but empirical research literature has usually only obtained the relevant factors affecting IPO underpricing, not to explain theoretically the fundamental reason for high IPO underpricing in China.

\section{Methods}

Firstly, by studying the impact of heterogeneous expectations on IPO underpricing in different ways of distribution, we raise heterogeneous expectations hypothesis-Institutional investors and retail investors in the assessment of the value of new shares have inevitable differences. According to this hypothesis, using behavioral finance theory and game theory, we establish respectively the pricing and underpricing models under fixed-price and bookbuilding, and does a comparative study between them. Secondly, we use Matlab make Numerical analysises.

\section{IPO underpricing models under different issuing mechanisms Problem description and assumed condition}

We assume that the issuing quantity of an offering is 1 , the underwriter invites not less than two institutional investors to participate in the offer, and all the institutional investors involved in bookbuilding are homogeneous. The issuer regulates the placing ratio of institutional investors as $k$ during the IPO issuing before bookbuilding, $k \in(0,1)$, and the placing amount of institutional investors during IPO issuing is $k$. Issuer 
determines the issuing price according to the total amount of their placing ratio after accumulating institutional investors' demands. Investors in the market can be divided into two types: institutional investors of the quantity $n$ and retail investors of the quantity $m$.

We assume that the issuer and institutional investors are rational enough and their priori estimate of the IPO intrinsic value is unbiased; it is deemed that the IPO intrinsic value is $V_{1} \rightarrow N\left(\bar{E}(U), \sigma_{1}^{2}\right)$; a priori estimate of the IPO intrinsic value of the retail investor is $V_{2}$ and a posteriori estimate of the IPO intrinsic value of investors is $V_{2} \sim V_{1}+\varepsilon\left(\bar{E}(U)+\varepsilon, \sigma_{1}^{2}\right)$, which is consistent with the conclusion that noise and rational traders can coexist in the same market in the long term, predicted by the DSSW model (De Long et al.).

Before the IPO subscription, all the investors will receive a private signal about $V_{1}$. Furthermore, we assume that the signal structure is $\varepsilon^{i} \sim N\left(0, \sigma_{2}^{2}\right)$ and $\varepsilon^{i}$ and $V_{1}$ are mutually independent, $i=1,2, \cdots, n+m$. Since different investors understand information differently, differences exist in the realized value of the signal. We assume that the realized value $s^{i}$ of $s^{i}$ is private information, however, the signal structure is common knowledge. To distinguish institutional and retail investors, we use $s^{i}(i=1,2, \cdots, n)$ and $s^{j}(j=1,2, \cdots, m)$ to express the private information of institutional and retail investors. The model is divided into two periods: in zero period, the issuer determines the IPO issuing price $p_{1}$ and conducts placement with investors; and in the first period, the IPO is transacted in the secondary market, the equilibrium market price is $p_{2}$, and we assume that the time interval between the issuing and the listing is short enough and that investors fail to get any new information during this period.

Under different issuing mechanisms, we define underpricing caused using investor estimates of the offering value as the unintentional underpricing and other underpricing elements caused by investor risk aversion as intentional underpricing (Xiaocheng et al. 2008).

\section{Determination of IPO issuing price under the fixed-price issuing mechanism}

Under the fixed-price issuing mechanism, since the issuer cannot determine the effective purchase demand, generally, the issuer will formulate the issuing price in strict accordance with the principle of expected utility maximization based on the determination of a risk aversion coefficient. To the greatest extent possible, without any reference of the IPO pricing, the issuer will formulate the IPO pricing close to its prospective value to avoid issuing failure risk or deficient IPO financing. As the IPO true value is unknown during pricing, The risk-averse issuer will maximize his expected utiliy according to the CARA utility function (He X and Yang C; 2008), The pricing of the expected utility maximization is listed below:

$$
E[U(V)]=-E X P\left[-\rho\left(\bar{E}(U)-\frac{1}{2} \rho \sigma_{1}^{2}\right)\right]=-E X P\left(-\rho p_{1}\right)
$$

Hence, IPO issuing price is

$$
p_{1}=\bar{E}(U)-\frac{1}{2} \rho \sigma_{1}^{2}
$$

The above formula indicates that under the fixed-price issuing mechanism, as the issuer expects to avoid pricing risk, $p_{1}$ and $\bar{E}(U)$ IPO prospective value are positively correlated, 
whereas $p_{1}$ and the risk aversion coefficient are negatively correlated. Therefore, when the issuer risk is neutral, namely $\rho=0$, the IPO issuing price is equal to the $\bar{E}(U)$ IPO prospective value. To avoid issuing failure or attract enough investors to participate in the IPO subscription, the issuer transfers a part of the risks to investors in the primary market, which is similar to the conclusions in Rock's (1986) "winner's curse" model.

After issuing, the stock is transacted in the secondary market. We assume that investors' optimal demand in the first period depends on the information gained at the beginning of the first period and the expectation of the IPO clearing price in the second period. Consequently, we make $I_{i j}, p_{3}(i=1,2, \cdots, n, j=1,2, \cdots m)$, respectively, stand for information gained by institutional and retail investors at the beginning of the first period and their expected IPO clearing price. Therefore, the obedience mean value of $p_{3}$ based on $I_{i j}$ conditional distribution is $E\left(p_{3} \mid I_{i j}\right)$ and the variance is normal distribution of $D\left(p_{3} \mid I_{i j}\right)$. According to investors' expected utility maximization $E\left[U\left(W_{i j}\right)\right]=$ $\operatorname{EXP}\left\{-\rho\left[\left(p_{3}-p_{2}\right) q_{1}\right]\right\}$, we solve its maximum value and we conclude that investors' optimal demand in the first period is $q_{1}=\frac{E\left(p_{3} \mid I_{i j}\right)-p_{2}}{\rho D\left(p_{3} \mid I_{i j}\right)}$.

Under the fixed-price issuing mechanism, the issuing price excludes any private investor information; hence, all investors only have their own private information in the first period. Based on Kyle's conclusions in 1989 and the above formula, we can obtain $i$ institutional investors' optimal demand at the moment as follows:

$$
q_{1}^{i}=\frac{\sigma_{2}^{2} \bar{E}(U)+\sigma_{1}^{2} s_{i}-\left(\sigma_{2}^{2}+\sigma_{1}^{2}\right) p_{2}}{\rho \sigma_{1}^{2} \sigma_{2}^{2}}
$$

In a similar way, $j$ retail investors' optimal demand in the first period is

$$
q_{1}^{j}=\frac{\sigma_{2}^{2} \bar{E}(U)+{\sigma_{1}}^{2} s_{j}+\left(\sigma_{2}^{2}+\sigma_{1}^{2}\right)\left(V_{2}-V_{1}-p_{2}\right)}{\rho \sigma_{1}^{2} \sigma_{2}^{2}}
$$

From the equilibrium condition of the secondary market $\sum_{i=1}^{n} q_{i}+\sum_{j=1}^{m} q_{j}=1$, we can conclude that the equilibrium market price $p_{2}$ in the first period is $p_{2}=$ $\frac{\sigma_{2}{ }^{2} \bar{E}(U)(n+m)+m\left(\sigma_{1}{ }^{2}+\sigma_{2}{ }^{2}\right)\left(V_{2}-V_{1}\right)+\sigma_{1}{ }^{2}\left(\sum_{i=1}^{n} s_{i}+\sum_{j=1}^{m} s_{j}\right)-\rho}{(n+m)\left(\sigma_{1}{ }^{2}+\sigma_{2}{ }^{2}\right)}$ when $m \rightarrow \infty, \quad \frac{m}{n+m} \rightarrow 1, \frac{n}{n+m} \rightarrow 0$, $\frac{\rho}{(n+m)\left(\sigma_{1}{ }^{2}+\sigma_{2}{ }^{2}\right)} \rightarrow 0$, according to law of large numbers, $\sum_{j=1}^{m} s_{j} / m \rightarrow \bar{E}(U)$; hence,

$$
p_{2}=\frac{\sigma_{2}^{2} \bar{E}(U)+\sigma_{1}^{2} \bar{E}(U)}{\sigma_{1}^{2}+\sigma_{2}^{2}}+V_{2}-V_{1}=\bar{E}(U)+V_{2}-V_{1} .
$$

According to formulas (1) and (2), under the fixed-price issuing mechanisms, the IPO prospective underpricing is

$$
U P_{1}=\frac{p_{2}-p_{1}}{p_{1}}=\frac{\rho \sigma_{1}^{2}+2\left(V_{2}-V_{1}\right)}{2 \bar{E}(U)-\rho \sigma_{1}^{2}}
$$

Based on the above formula (3), under fixed-price issuing, the IPO underpricing can be divided into $\frac{\rho \sigma_{1}{ }^{2}}{2 \bar{E}(U)-\rho \sigma_{1}{ }^{2}}$ and $\frac{2\left(V_{2}-V_{1}\right)}{2 \bar{E}(U)-\rho \sigma_{1}{ }^{2}}$. According to the abovementioned definition, the former is led by investor risk aversion, which is intentional underpricing, whereas the latter is led by investor heterogeneity, which is unintentional underpricing. In addition, IPO underpricing and $V_{2}-V_{1}$ are positively correlated, namely the larger the investor nonhomogenous expectations, the larger the unintentional underpricing and IPO underpricing, 
which indicates that under the fixed-price issuing; the unintentional underpricing caused by investor non-homogenous expectations is one reason for IPO high underpricing.

\section{Determination of IPO issuing price under the bookbuilding issuing mechanism}

Under the bookbuilding mechanism, the issuer first invites institutional investors for tender offers and determines the issuing price according to their offer information and total amount of placements, and the rest of the shares are placed with retail investors based on the issuing price. Rational institutional investors generally take the estimate of the IPO intrinsic value as the offer basis during the purchase offer. The placement rule for institutional investors' quantity discrimination can lead to truthful disclosure of private information during IPO bookbuilding (Benveniste and Spindt, 1989); therefore, this paper excludes the possibility of investors hiding information. Although in practice, institutional investors only report limited pair (price and quantity demand) combinations, this paper assumes that they report continuous demand curves to simplify the analysis.

In zero period, $i$ institutional investors only have private information $s_{i}$ of their own; hence, the posteriori estimate of IPO intrinsic value $V$ is $E\left(V \mid s_{i}\right)=\frac{\sigma_{2}{ }^{2} \bar{E}(U)+\sigma_{1}{ }^{2} s_{i}}{\sigma_{1}{ }^{2}+\sigma_{2}{ }^{2}}$, $D\left(V \mid s_{i}\right)=\frac{\sigma_{1}{ }^{2} \sigma_{2}{ }^{2}}{\sigma_{1}{ }^{2}+\sigma_{2}{ }^{2}}$, and its optimal demand in zero period is $q_{i}=\frac{\sigma_{2}{ }^{2} \bar{E}(U)+\sigma_{1}{ }^{2} s_{i}-\left(\sigma_{1}{ }^{2}+\sigma_{2}{ }^{2}\right) p_{1}}{\rho \sigma_{1}{ }^{2} \sigma_{2}{ }^{2}}$.

We assume that $k \leq 1$ is the placing ratio for institutional investors, and according to the equilibrium condition of the primary market $\sum_{i=1}^{n} s_{i}=k$, we can solve the IPO issuing price as follows:

$$
p_{1}=\frac{n \sigma_{2}{ }^{2} \bar{E}(U)+\sigma_{1}{ }^{2} \sum_{i=1}^{n} s_{i}-\rho k}{n\left(\sigma_{1}{ }^{2}+\sigma_{2}{ }^{2}\right)}
$$

According to (4), we can conclude that under the issuing mechanism of bookbuilding, a monotone, increasing linear corresponding relation exists between the IPO issuing price and institutional investor private information $\sum_{i=1}^{n} s_{i}$. Therefore, participants may infer $\sum_{i=1}^{n} s_{i}$ by virtue of the issuing price, and at the end of the zero period, institutional investor private information $\sum_{i=1}^{n} s_{i}$ will become participant common knowledge.

In the first period, since institutional investor private information $\sum_{i=1}^{n} s_{i}$ will become participant common knowledge, their conditional expectations and the variance of equilibrium price in the second period are represented by $E\left(V_{1} \mid \sum_{i=1}^{n} s_{i}\right)=$ $\frac{\sigma_{2}{ }^{2} \bar{E}(U)+\sigma_{1}{ }^{2} \sum_{i=1}^{n} s_{i}}{n \sigma_{1}{ }^{2}+\sigma_{2}{ }^{2}}$ and $D\left(V \mid \sum_{i=1}^{n} s_{1}\right)=\frac{\sigma_{1}{ }^{2}+\sigma_{2}{ }^{2}}{n \sigma_{1}{ }^{2}+\sigma_{2}{ }^{2}}$.

Combined with Kyle's results (1989) and the above formula, Their optimal demand in the first period is: $q_{i}=\frac{\sigma_{2}{ }^{2} \bar{E}(U)+\sigma_{1}{ }^{2} \sum_{i=1}^{n} s_{i}-\left(n \sigma_{1}{ }^{2}+\sigma_{2}{ }^{2}\right) p_{2}}{\rho \sigma_{1}{ }^{2} \sigma_{2}{ }^{2}}$.

In the first period, besides their own private information, retail investors $j$ also master institutional investors' private information; hence, their conditional expectations and variance of equilibrium price in the first period are represented by $E\left(V_{2} \mid \sum_{i=1}^{n} s_{i}, s_{j}\right)=$ $\frac{\sigma_{2}{ }^{2} \bar{E}(U)+\sigma_{1}{ }^{2}\left(\sum_{i=1}^{n} s_{i}+s_{j}\right)}{(n+1) \sigma_{1}{ }^{2}+\sigma_{2}{ }^{2}}+V_{2}-V_{1}$ and $D\left(V_{2} \mid \sum_{i=1}^{n} s_{i}, s_{j}\right)=\frac{\sigma_{1}{ }^{2} \sigma_{2}{ }^{2}}{(n+1) \sigma_{1}{ }^{2}+\sigma_{2}{ }^{2}}$. 
Then, their optimal demand in the first period is

$$
q_{j}=\frac{\sigma_{2}^{2} \bar{E}(U)+\sigma_{1}^{2}\left(\sum_{i=1}^{n} s_{i}+s_{j}\right)-\left[(n+1) \sigma_{1}{ }^{2}+\sigma_{2}^{2}\right]\left(V_{2}-V_{1}-p_{2}\right)}{\rho \sigma_{1}^{2}{\sigma_{2}}^{2}}
$$

When the equilibrium condition $\sum_{i=1}^{n} q_{i}+\sum_{j=1}^{m} q_{j}=1$ and $m \rightarrow \infty$, we obtain the equilibrium price of the secondary market:

$$
p_{2}=\frac{\sigma_{2}^{2} \bar{E}(U)+\sigma_{1}^{2} V-n \sigma_{1}^{2} \sum_{i=1}^{n} s_{i}}{(n+1) \sigma_{1}{ }^{2}+\sigma_{2}{ }^{2}}+V_{2}-V_{1} .
$$

From formulas (4) and (5), we can obtain the IPO prospective underpricing under bookbuilding:

$$
U P_{2}=\frac{p_{2}-p_{1}}{p_{1}}=\frac{k \rho \sigma_{1}^{2} \sigma_{2}^{2}+n\left(\sigma_{1}^{2}+\sigma_{2}^{2}\right)\left(V_{2}-V_{1}\right)}{n \bar{E}(U)\left(\sigma_{1}^{2}+\sigma_{2}^{2}\right)-k \rho \sigma_{1}^{2} \sigma_{2}^{2}}
$$

According to formula (6), the former $\frac{k \rho \sigma_{1}{ }^{2} \sigma_{2}{ }^{2}}{n \bar{E}(U)\left(\sigma_{1}^{2}+\sigma_{2}^{2}\right)-k \rho \sigma_{1}{ }^{2} \sigma_{2}{ }^{2}}$ is led by investor risk aversion, which is intentional underpricing, whereas the latter $\frac{n\left(\sigma_{1}{ }^{2}+\sigma_{2}{ }^{2}\right)\left(V_{2}-V_{1}\right)}{n E(U)\left(\sigma_{1}{ }^{2}+\sigma_{2}{ }^{2}\right)-k \rho \sigma_{1}{ }^{2} \sigma_{2}{ }^{2}}$ is led by investor heterogeneity, which is unintentional underpricing. From formula (6), we can directly reach a conclusion that IPO underpricing and degree of risk aversion as well as investor heterogeneous estimates of the offering value are positively correlated. Since IPO underpricing is positively correlated with $V_{2}-V_{1}$ under bookbuilding-namely the larger of the investors' non-homogenous expectations, the higher of the unintentional underpricing or IPO underpricing, which indicates that the unintentional underpricing caused by investor non-homogenous expectations is one of the main cause of the IPO high-underpricing under bookbuilding.

\section{Comparative analysis of IPO underpricing}

The results of the IPO underpricing model under the two types of issuing mechanisms can be summarized as follows:

According to the above Table 1, we can conclude the following:

Conclusion one: Issuing stock either by fixed price or bookbuilding fails to eliminate IPO underpricing.

The above Table 1 shows that IPO underpricing exists under both issuing mechanisms, and that the IPO underpricing, degree of risk aversion, and retail investor estimates of the offering value are positively correlated, whereas the IPO underpricing and the institutional investor estimates of the offering value and the intrinsic value of the offering are negatively correlated. Under fixed-price issuing, the IPO intentional underpricing is only related to the issuer's degree of risk aversion, and the unintentional underpricing is related to institutional and retail investors' estimates of the offering value (non-homogenous expectations). However, under bookbuilding, intentional underpricing is not only related to institutional investor estimates of the offering value but also to the placing ratio of the offering and institution quantity, and the unintentional underpricing is related to investor degree of heterogeneity, placing ratio, and institution quantity. The degree of risk aversion cannot be controlled; therefore, a 
Table 1 Comparison of IPO pricing and underpricing under fixed-price and bookbuilding issuing. The table shows the issuing pricing、 Equilibrium price of secondary market、 IPO intentional underpricing and unintentional underpricing under Fixed-price issuing and Bookbuilding issuing. The results come from the IPO underpricing model (3) and model (6). The table are shown as follows:

\begin{tabular}{llllll}
\hline Issuing way & Issuing price & Equilibrium price of secondary market & IPO underpricing & Intentional underpricing & Unintentional underpricing (non-homogenous expectation) \\
\hline Fixed-price issuing & $\bar{E}(U)-\frac{1}{2} \rho \sigma_{1}{ }^{2}$ & $\bar{E}(U)+V_{2}-V$ & $\frac{\rho \sigma_{1}{ }^{2}+2\left(V_{2}-V_{1}\right)}{2 E(U)-\rho \sigma_{1}{ }^{2}}$ & $\frac{\rho \sigma_{1}{ }^{2}}{2 E(U)-\rho \sigma_{1}{ }^{2}}$ & $\frac{2\left(V_{2}-V_{1}\right)}{2 E(U)-\rho \sigma_{1}{ }^{2}}$ \\
\hline Book building issuing & $\frac{n \sigma_{2}{ }^{2} \bar{E}(U)+\sigma_{1}{ }^{2} \sum_{i=1}^{n} s_{i}-\rho k}{n\left(\sigma_{1}{ }^{2}+\sigma_{2}{ }^{2}\right)}$ & $\frac{\sigma_{2}{ }^{2} \bar{E}(U)+\sigma_{1}{ }^{2} V-n \sigma_{1}{ }^{2} \sum_{i=1}^{n} S_{i}}{(n+1) \sigma_{1}{ }^{2}+\sigma_{2}{ }^{2}}+V_{2}-V_{1}$ & $\frac{k \rho \sigma_{1}{ }^{2} \sigma_{2}{ }^{2}+n\left(\sigma_{1}{ }^{2}+\sigma_{2}{ }^{2}\right)\left(V_{2}-V_{1}\right)}{n E(U)\left(\sigma_{1}{ }^{2}+\sigma_{2}{ }^{2}\right)-k \rho \sigma_{1}{ }^{2} \sigma_{2}{ }^{2}}$ & $\frac{k \rho \sigma_{1}{ }^{2} \sigma^{2}{ }^{2}}{n E(U)\left(\sigma_{1}{ }^{2}+\sigma_{2}{ }^{2}\right)-k \rho \sigma_{1}{ }^{2} \sigma_{2}{ }^{2}}$ & $\frac{n\left(\sigma_{1}{ }^{2}+\sigma_{2}{ }^{2}\right)\left(V_{2}-V_{1}\right)}{n E(U)\left(\sigma_{1}{ }^{2}+\sigma_{2}{ }^{2}\right)-k \rho \sigma_{1}{ }^{2} \sigma_{2}{ }^{2}}$ \\
\hline
\end{tabular}


policy for conclusion one suggests strengthening information disclosure and investor training, and decreasing irrational investment and investor non-homogenous expectations to further lower unintentional underpricing and IPO underpricing.

Conclusion two: The larger the investor non-homogenous expectations, the higher the IPO underpricing. Under the fixed-price issuing mechanism, the IPO underpricing is $\frac{\sigma_{1}^{2} \bar{E}(U)}{2 \bar{E}(U)-\rho \sigma_{1}{ }^{2}}+\frac{2\left(V_{2}-V_{1}\right)}{2 \bar{E}(U)-\rho \sigma_{1}{ }^{2}}$. The first part is the prospective underpricing led by issuer's intentional cut-rate prices to avoid risk, and the second is the unintentional underpricing caused by institutional and retail investors' heterogeneity. This reveals that the larger the non-homogenous expectations, namely $V_{2}-V_{1}$, the higher the IPO underpricing. Therefore, under the two different issuing mechanisms, the larger the investors' non-homogenous expectation, the larger the unintentional and IPO underpricing. Conclusion two indicates, under either issuing mechanism, IPO high underpricing is not only caused by intentional underpricing of the issuer and institution but also by unintentional underpricing from investor heterogeneity. Hence, to reduce IPO high underpricing, not only intentional underpricing should be decreased but also heterogeneity among investors should be eliminated, further lowering unintentional underpricing and IPO high underpricing. The economic meaning of conclusion two lies in decreasing information asymmetry by enhancing IPO information disclosure and investor rational education, and further investor divergence (non-homogenous expectations) on offering values can be reduced and unintentional underpricing can be lowered as well.

Conclusion three: Under the same condition, compared with fixed-price, IPO prospective underpricing is much lower under bookbuilding.

Through comparison between formulas (3) and (6), we know that when $n \geq 2$, IPO underpricing under bookbuilding is $\frac{k \rho \sigma_{1}{ }^{2} \sigma_{2}{ }^{2}}{n \bar{E}(U)\left(\sigma_{1}{ }^{2}+\sigma_{2}{ }^{2}\right)-k \rho \sigma_{1}{ }^{2} \sigma_{2}{ }^{2}}+\frac{n\left(\sigma_{1}{ }^{2}+\sigma_{2}{ }^{2}\right)\left(V_{2}-V_{1}\right)}{n E(U)\left(\sigma_{1}{ }^{2}+\sigma_{2}{ }^{2}\right)-k \rho \sigma_{1}{ }^{2} \sigma_{2}}$. After the numerator and denominator of this formula are simultaneously divided by $\sigma_{2}^{2}$, we obtain $\frac{k \rho \sigma_{1}^{2}}{n \bar{E}(U)\left(\frac{\sigma_{1}^{2}}{\sigma_{2}{ }^{2}}+1\right)-k \rho \sigma_{1}{ }^{2}}+\frac{n\left(\frac{\sigma_{1}{ }^{2}}{\sigma_{2}}+1\right)\left(V_{2}-V_{1}\right)}{n \bar{E}(U)\left(\frac{\sigma_{1}^{2}}{\sigma_{2}{ }^{2}}+1\right)-k \rho \sigma_{1}{ }^{2}}$. Obviously, $n \bar{E}(U)\left(\frac{\sigma_{1}{ }^{2}}{\sigma_{2}{ }^{2}}+1\right)-k \rho \sigma_{1}{ }^{2} \geq 2 \bar{E}(U)-\rho \sigma_{1}{ }^{2}$. However, $\frac{n\left(\sigma_{1}{ }^{2}+\sigma_{2}{ }^{2}\right)}{n E(U)\left(\sigma_{1}{ }^{2}+\sigma_{2}{ }^{2}\right)-k \rho \sigma_{1}{ }^{2} \sigma_{2}{ }^{2}} \leq \frac{2}{2 E(U)-\rho \sigma_{1}{ }^{2}}$; hence, $U P_{2} \leq U P_{1}$. In the meantime, due to $\frac{n\left(\sigma_{1}{ }^{2}+\sigma_{2}{ }^{2}\right)}{n \bar{E}(U)\left(\sigma_{1}{ }^{2}+\sigma_{2}{ }^{2}\right)-k \rho \sigma_{1}{ }^{2} \sigma_{2}{ }^{2}} \leq \frac{2}{2 \bar{E}(U)-\rho \sigma_{1}{ }^{2}}$, unintentional underpricing caused by investors non-homogenous expectations under bookbuilding is much lower than that under the fixed-price mechanism, which is consistent with the research results of Benveniste et al. (2002). The economic meaning of conclusion three lies in strengthening information disclosure and supervision of offerings, making more investors participate in offer pricing and decreasing non-homogenous expectations among investors, information asymmetry, and IPO unintentional underpricing to further lower IPO high-underpricing, since bookbuilding and fixed-price issuing offers higher pricing efficiency. Under bookbuilding, institutional investor intentional underpricing can be reduced by adding institution quantity and decreasing the placing ratio of the offering. Hence, more institutions will participate in the IPO subscription through the enhancing training force of the institution; thus, the IPO intentional underpricing can be reduced and further IPO high-underpricing can be prevented in two ways.

Conclusion four: Under bookbuilding, if investor non-homogenous expectations become larger, IPO underpricing may be much higher than that under fixed-price issuing. 
Based on the above analysis, we know that under the same conditions, IPO underpricing using bookbuilding may be lower than that using the fixed-price method. However, under bookbuilding, when $V_{2}-V_{1}$ is larger than $V_{2}-V_{1}$ under the fixed-price method, though $\frac{n\left(\sigma_{1}{ }^{2}+\sigma_{2}{ }^{2}\right)}{n \bar{E}(U)\left(\sigma_{1}{ }^{2}+\sigma_{2}{ }^{2}\right)-k \rho \sigma_{1}{ }^{2} \sigma_{2}{ }^{2}} \leq \frac{2}{2 \bar{E}(U)-\rho \sigma_{1}{ }^{2}}, \frac{n\left(\sigma_{1}{ }^{2}+\sigma_{2}{ }^{2}\right)\left(V_{2}-V_{1}\right)}{n \bar{E}(U)\left(\sigma_{1}{ }^{2}+\sigma_{2}{ }^{2}\right)-k \rho \sigma_{1}{ }^{2} \sigma_{2}{ }^{2}}$ may be larger than $\frac{2\left(V_{2}-V_{1}\right)}{2 E(U)-\rho \sigma_{1}^{2}}$, which is to say that unintentional underpricing caused by investor nonhomogenous expectations changes. When $\frac{n\left(\sigma_{1}{ }^{2}+\sigma_{2}{ }^{2}\right)\left(V_{2}-V_{1}\right)}{n E(U)\left(\sigma_{1}{ }^{2}+\sigma_{2}{ }^{2}\right)-k \rho \sigma_{1}{ }^{2} \sigma_{2}{ }^{2}}$ is larger than $\frac{\rho \sigma_{1}^{2}+2\left(V_{2}-V_{1}\right)}{2 \bar{E}(U)-\rho \sigma_{1}{ }^{2}}+\frac{k \rho \sigma_{1}{ }^{2} \sigma_{2}{ }^{2}}{n \bar{E}(U)\left(\sigma_{1}{ }^{2}+\sigma_{2}{ }^{2}\right)-k \rho \sigma_{1}{ }^{2} \sigma_{2}{ }^{2}}$, IPO underpricing under bookbuilding is surely larger than that under fixed-price. The economic meaning of conclusion four lies in the fact that the market-oriented bookbuilding mechanism does not always reduce IPO underpricing when investor non-homogenous expectations are different under the different issuing mechanisms. Therefore, when bookbuilding is adopted in China, only by strengthening investor rational education, decreasing non-homogenous expectations between institutional and retail investors and IPO information asymmetry, and enhancing supervision can real marketization of the bookbuilding mechanism be realized, thus further lowering IPO underpricing and improving IPO pricing efficiency.

\section{Numerical analysis}

To discuss IPO pricing efficiency under different pricing mechanisms and provide numerical support for our results, we look at an example of a company IPO and apply the underpricing model to conduct a numerical and comparative analysis of the fixedprice and bookbuilding to gain a better understanding of management during the IPO process. Matlab software is used to do the numerical simulation as follows:

1) Under the same condition of investor non-homogenous expectations, the risk aversion coefficient's influence on IPO underpricing under the different issuing mechanisms.

We make $n=10, k=0.65 \rho=2, \sigma_{1}^{2}=1, \sigma_{2}^{2}=2.5, \bar{E}(U)=12.6, V_{2}=14.5, V_{1}=11.46$, adopt the abovementioned parameters, and use Matlab to plot and discuss the relation between IPO underpricing and $\rho . \rho \in[0,4], \sigma^{2} \in[0,4]$. The figures are shown as follows:

In Fig. 1, UP1 is IPO underpricing under the fixed-price mechanism and UP2 is IPO underpricing under bookbuilding. The results show that under the two different pricing mechanisms, IPO underpricing and $\rho$ and $\sigma_{1}^{2}$ are positively correlated, and both are larger than zero, namely the larger the issuer and institutional investor aversion risk, the higher the IPO underpricing. However, under the same conditions, compared with the fixed-price mechanism, the IPO underpricing under bookbuilding is much lower, which illustrates that under the same conditions, bookbuilding offers much higher pricing efficiency than the fixed-price method, and further corroborates conclusions one and three.

2) Investor non-homogenous expectations' influence on IPO underpricing under different issuing mechanisms.

We adopt the abovementioned parameters to discuss the relation between IPO underpricing and investor non-homogenous expectations, and use Matlab to plot 


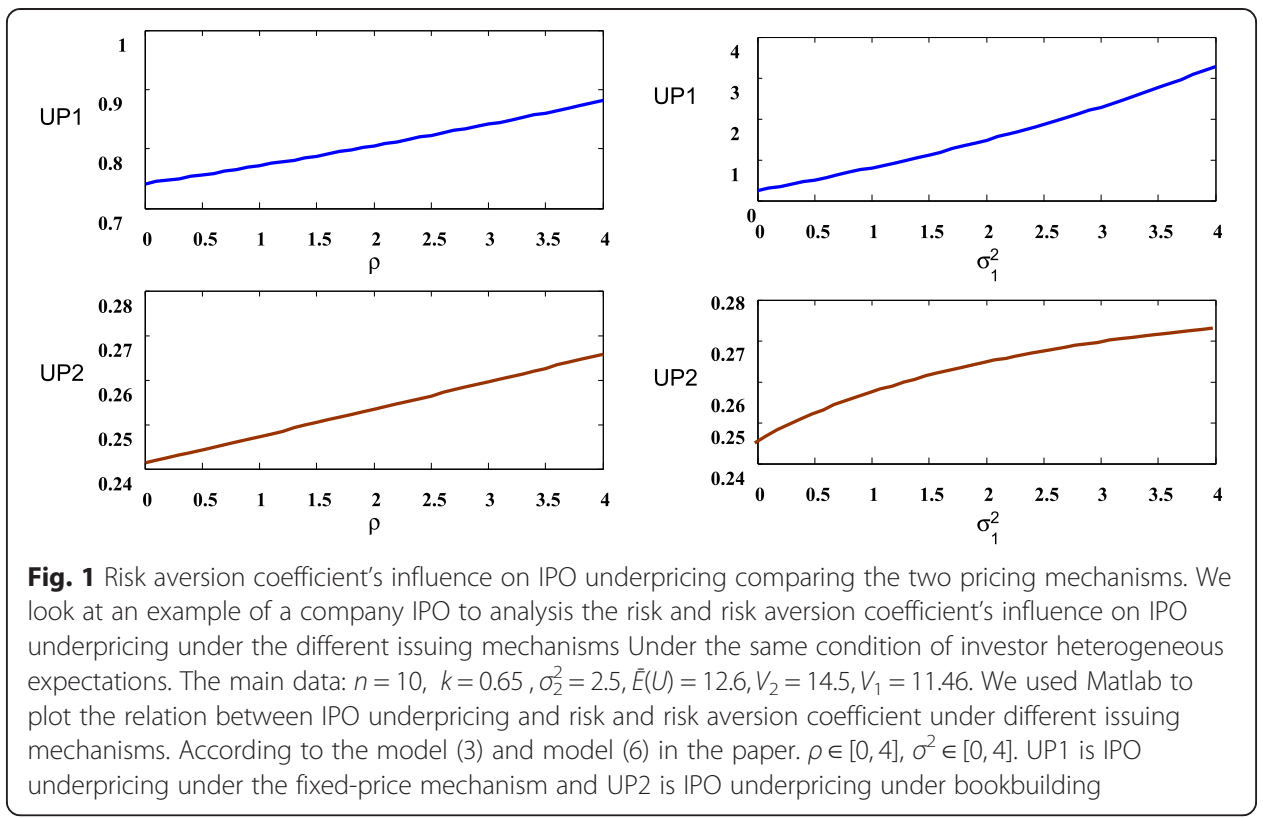

the relation between IPO underpricing and $V_{1}, V_{2} . V_{1} \in[8,16], V_{2} \in[8,16]$. The figures are shown as follows:

Figure 2 shows that IPO underpricing and $V_{2}$ are positively correlated, and that IPO underpricing and $V_{1}$ are negatively correlated. In other words, the more optimistic retail investor attitude is toward the IPO prospect, the higher the unintentional underpricing, which confirms conclusion two above. When $V_{2}=8$, $V_{1}=16$, and $V_{2}-V_{1}$ is smaller, although non-homogenous expectations among investors are larger, unintentional underpricing is negative, and although intentional underpricing is positive, it fails to eliminate the influence of investor non-homogenous expectations on IPO underpricing. Through comparisons of the graphs in Fig. 2, under the same conditions, IPO underpricing is within -0.25 and 0.9 under fixed-price issuing, whereas IPO underpricing is within -0.75 and 0.45 under bookbuilding; compared with fixed price, IPO underpricing is much lower under bookbuilding, which explains why, under the same conditions, bookbuilding offers much higher pricing efficiency than fixed price, and further demonstrates conclusions one and three. The above figures show that under the same circumstances, when investor non-homogenous expectations are larger under bookbuilding than under fixed price, IPO underpricing under bookbuilding may be equal to or higher than that under fixed price. This illustrates that bookbuilding does not always reduce IPO underpricing and further demonstrates conclusion four.

3) Different investor non-homogenous expectations' influence on IPO underpricing under different issuing mechanisms.

To further demonstrate conclusion four, we adopt the above parameters to discuss different investor non-homogenous expectations' influence on IPO underpricing under the different issuing mechanisms. We assume investor estimates of offering value under bookbuilding as $V_{2}=16.5, V_{1}=11.46$ and investor estimates of offering value under fixed price as $V_{2}=14.5, V_{1}=11.46$; thus, investor non-homogenous expectations under bookbuilding are larger $(16.5-11.46=5.01)$ than those under 


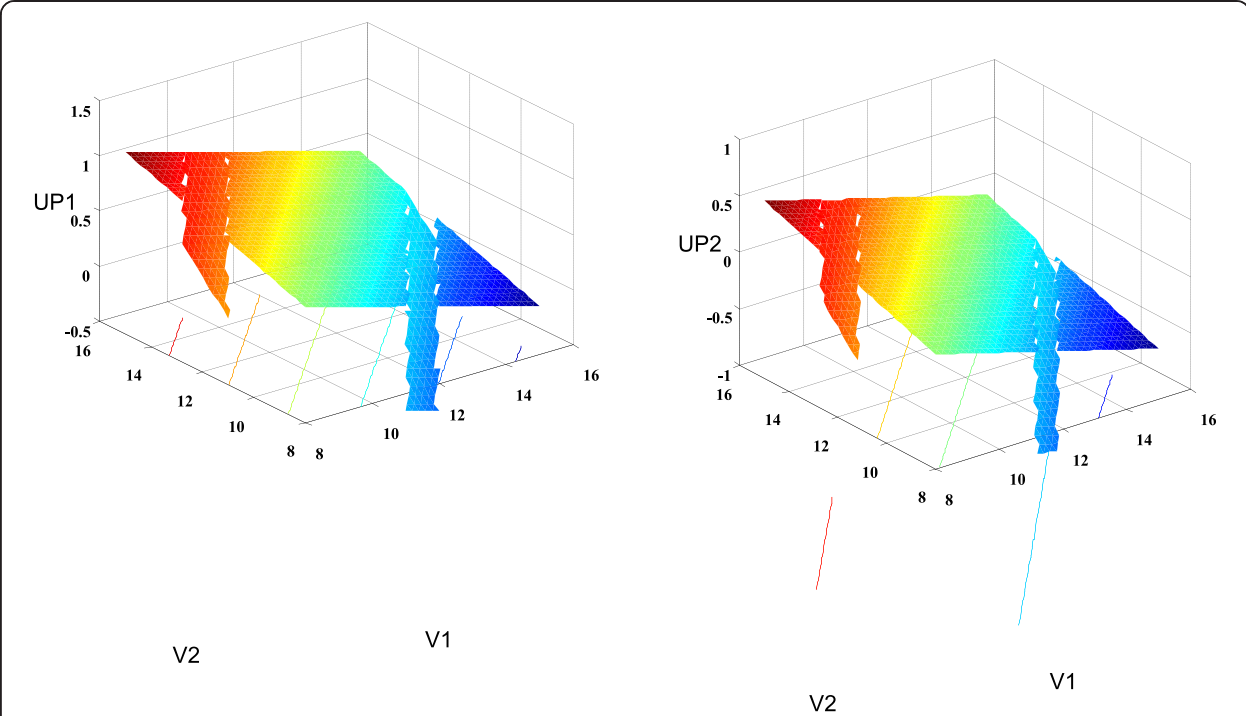

Fig. 2 Relation between IPO underpricing and $V_{1}, V_{2}$ under different issuing mechanism. We use the data $V_{1} \in[8,16], V_{2} \in[8,16], n=10, k=0.65 \rho=2, \sigma_{1}^{2}=1, \sigma_{2}^{2}=2.5$, discuss the relation between IPO underpricing and investors' heterogeneous expectations, and use Matlab to plot the relation between IPO underpricing and $V_{1}, V_{2}$. According to the model (3) and model (6) in the paper. UP1 is IPO underpricing under the fixed-price mechanism and UP2 is IPO underpricing under bookbuilding

fixed price (14.5-11.46=3.01). We then use Matlab to plot and discuss the relation between IPO underpricing and $\rho$ and $\sigma_{1}^{2} . \rho \in[0,4], \sigma^{2} \in[0,4]$. The figures are shown as follows:

In Fig. 3, UP1 is IPO underpricing under fixed-price and UP2 is IPO underpricing under bookbuilding. Based on Fig. 3, we know that when $\rho \leq 3$ or $\sigma_{1}^{2} \leq 2$, IPO underpricing under bookbuilding is larger than that under fixed-price, which explains why IPO underpricing under bookbuilding may also be much higher than that under fixed price when investor non-homogenous expectations under bookbuilding are larger than those under fixed price, and further illustrates conclusion four.

\section{Results and discussion}

Results: Through the above study, we got the following results:

1) Issuing stock either by fixed price or bookbuilding fails to eliminate IPO underpricing.

2) The larger the investor non-homogenous expectations, the higher the IPO underpricing.

3) Under the same condition, compared with fixed-price, IPO prospective underpricing is much lower under bookbuilding.

4) Under bookbuilding, if investor non-homogenous expectations become larger, IPO underpricing may be much higher than that under fixed-price issuing.

Discussion: IPO equilibrium pricing and underpricing models in this paper are obtained based on assumptions of the issuer and institutional investor's risk aversion and the heterogeneity of institutional and retail investors. In case these assumptions are removed, especially the heterogeneity of all the investors, it will be extremely difficult to solve the 


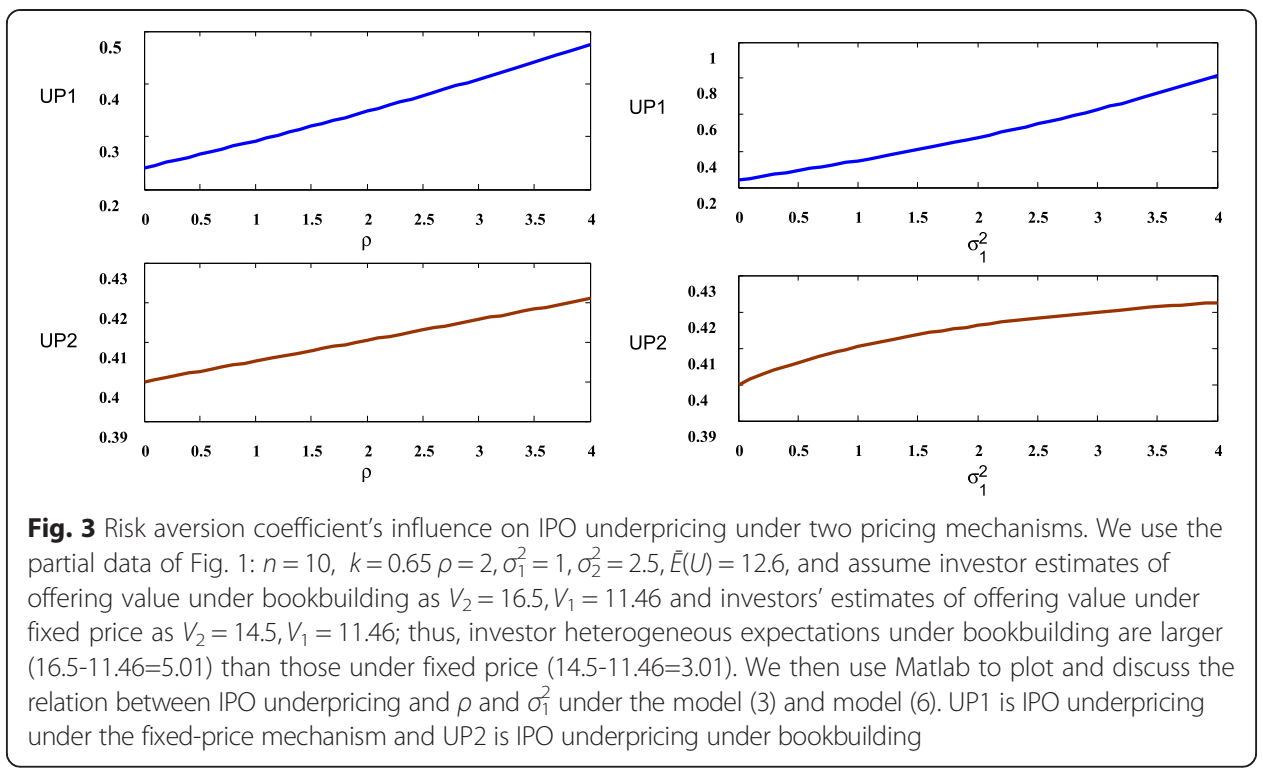

analytical expression of the optimized quotation under different circumstances. This is a limitation of this paper as well as a problem worthy of further investigation.

\section{Conclusions}

Through the comparative study of IPO underpricing under different issuing mechanisms, we reach the following conclusions. Issuing stock using either the fixed price or bookbuilding cannot eliminate IPO underpricing. Under both mechanisms, the larger the investor non-homogenous expectations, the larger the IPO underpricing. Compared with the fixed price, unintentional underpricing caused by non-homogenous expectations under bookbuilding and IPO underpricing are much lower. In the case when investor non-homogenous expectations are much larger, compared with fixed price, IPO underpricing under bookbuilding may be much higher than that under fixed price. Finally, through the numerical analysis, this paper obtains a better management understanding and provides quantitative support for its conclusions. Different from previous research conclusions, this paper not only theoretically explains the reasons why the issuing mechanism of bookbuilding offers a much higher IPO pricing coefficient than that of fixed price but also explains why the bookbuilding mechanism does not always reduce IPO underpricing from the perspective of investor non-homogenous expectations.

The issuing mechanism of bookbuilding offers a much higher IPO pricing coefficient than that of fixed-price on the condition that non-homogenous expectations among investors remain unchanged. Once non-homogenous expectations among investors increase, this may cause the IPO underpricing under bookbuilding to become even higher. Hence, when the issuing mechanism of bookbuilding is adopted in China, only by decreasing non-homogenous expectations among institutional investors can real marketization of bookbuilding be given full play, further lowering IPO highunderpricing. 
Authors' contributions

XZ carried out the IPO pricing and underpricing model studies, participated in the numerical analysis and drafted the manuscript. MZ carried out the data collection. Profesor Xiaoan Huang participated in the design of the study and performed the numerical analysis. Profesor $Y Z$ participated in coordination and helped to draft the manuscript. All authors read and approved the final manuscript.

\section{Acknowledgements}

We are grateful to the financial supports from National Natural Science Foundation of China (71361005): Mechanism of IPO underpricing based on investors' observed and unobserved heterogeneity.

\section{Author details}

${ }^{1}$ School of Management, Guilin University of Technology, 12 Jian gan road, Seven Star District, Guilin 541001, Peoples Republic of China. ${ }^{2}$ School of Economics, Central University of Finance and Economics, 39 South College Road, Haidian District, Beijing 100081, Peoples Republic of China.

Received: 11 May 2015 Accepted: 18 June 2015

Published online: 18 September 2015

\section{References}

Beneda N, Zhang Y (2009) Heterogeneous relationship between IPO return and risk across idiosyncratic variance characteristics. Q Rev Econ Finance 49:1298-1316

Benveniste LM, Spindt PA (1989) How investment bankers determine the offer price and allocation of new issues. J Financ Econo 24(2):343-362

Benveniste LM, Busaba WY, Wilhelm WJ (2002) Information externalities and the role of underwriters in primary equity markets. J Financ Intermed 11(1):61-86

Ge H, Lin L (2011) Behavior Pattern of Institutional Investors and Its Influence on Market Pricing Efficient [J]. System Engineering 29(2):21-26

Gouldey BK (2006) Uncertain Demand: Non-homogenous expectations, and Unintentional IPO Underpricing. The Finance Review 41:33-54

He X, Yang C (2008) Utility Function and Doer: Interpretation from the Perspective of Financial Economics. Finance Theory and Practice 29(5):2-7

Kyle AS (1989) Informed speculation with imperfect competition. Rev Econ Stud 56:317-356

Liao S (2010) Research on Pricing Efficiency of Chinese Stock Market_—_Based on the Perspective of Specific Information Content of Individual Share. J Financ Econ 8:68-77

Ljungqvist, A, V. Nanda, and R. Singh Hot Markets, Investor Sentiment, and IPO Pricing. Journal of Business 2004. forthcoming

Miller EM (1977) Risk, uncertainty, and divergence of opinion. J Financ 32:1151-1168

Ritter JR (1991) The Long-Run Performance of Initial Public Offerings. J Finance 46:3-27

Rock K (1986) Why New Issues Are Underpriced. J Financ Econ 15:187-212

Xiaocheng Z, Weidong M, Xiaohua Z (2008) Non-homogenous expectation's Influence on IPO Underpricing under Bookbuilding. Chinese Journal of Management Science 16(6):168-175

Xiaocheng Z, Weidong M, Xiaohua Z (2011) Research on Institutional Investors' Non-homogenous Expectation's Influence on IPO Underpricing. J Syst Eng 2:195-202

Xiaohua Z, Weike Z, Xing L (2006) Comparative Research of IPO Pricing Efficiency under Examination and Approval system and Authorization System of Chinese Stock Issue. Management World 11:13-18

\section{Submit your manuscript to a SpringerOpen ${ }^{\circ}$ journal and benefit from:}

- Convenient online submission

Rigorous peer review

- Immediate publication on acceptance

- Open access: articles freely available online

- High visibility within the field

- Retaining the copyright to your article 